\title{
QUALIDADE FISIOLÓGICA DE SEMENTES DE Euterpe edulis Mart. SUBMETIDAS A TÉCNICAS CASEIRAS DE DESPOLPAMENTO
}

\author{
Lorena Abdalla de Oliveira Prata Guimarães ${ }^{1}$ \\ Roberta Guimarães de Souza² \\ Maristela Aparecida Dias Guimarães ${ }^{3}$ \\ Maurício Lima Dan ${ }^{4}$ \\ Guilherme Carneiro de Mendonça ${ }^{5}$
}

\begin{abstract}
Resumo: A germinação de sementes da Euterpe edulis (juçara) ocorre de forma lenta e desuniforme, mas a remoção do pericarpo elou a escarificação podem facilitar a germinação. O objetivo deste estudo foi avaliar o efeito de métodos caseiros de despolpamento sobre a emergência e o vigor de plântulas de juçara. Foram aplicados quatro métodos de despolpamento: imersão dos frutos em água a $65^{\circ} \mathrm{C}$ por $3 \mathrm{~h}$ e extração da polpa com peneira (T1) e liquidificador (T2); imersão dos frutos em água fria (temperatura ambiente) por 24 h e extração da polpa com peneira (T3) e liquidificador (T4). As sementes despolpadas foram distribuídas em bandejas contendo areia e irrigadas diariamente. Após 102 dias foram avaliadas a emergência e o vigor das plântulas. Apenas a emergência apresentou respostas significativas aos tratamentos. $O$ vigor das plântulas de juçara não é influenciado pelos métodos de despolpamento testados. Entretanto, a imersão em água fria por 24 horas e a extração da polpa com liquidificador são mais favoráveis à emergência das plântulas.
\end{abstract}

Palavras-chave: Palmeira juçara; Espécie em risco de extinção; Germinação; Vigor de plântulas.

\footnotetext{
${ }^{1}$ Incaper/CRDR Centro Serrano, Brasil. E-mail: lorena.prata@hotmail.com.

2 D.Sc. Ecologia, Brasil. E-mail: rosouza@yahoo.com.

3 IF Goiano/Fitotecnia, Iporá-GO, Brasil. E-mail: maristela.dias@ifgoiano.edu.br.

${ }^{4}$ Incaper/CRDR Centro Serrano, Brasil. E-mail: mauricioldan@gmail.com.

5 lema/Programa Reflorestar, Domingos Martins-ES, Brasil. E-mail: guic_m@yahoo.com.br.
} 